\title{
ANTI-ATHEROSCLEROTIC ACTIVITY OF ETHANOLIC EXTRACT OF CHRYSANTHEMUM INDICUM L. FLOWERS AGAINST HIGH-FAT DIET-INDUCED ATHEROSCLEROSIS IN MALE WISTAR RATS
}

\author{
SRAVANTHI P' ${ }^{*}$, SHAKIR BASHA $\mathbf{S}^{2}$ \\ ${ }^{1}$ Department of Pharmacology, Sree Vidyanikethan College of Pharmacy, A. Rangampet, Tirupati - 517 102, Andhra Pradesh, India. \\ ${ }^{2}$ Department of Pharmaceutical Analysis, Sree Vidyanikethan College of Pharmacy, A. Rangampet, Tirupati - 517 102, Andhra Pradesh, \\ India. Email: sravanthip29@gmail.com
}

Received: 01 May 2017, Revised and Accepted: 22 May 2017

\begin{abstract}
Objective: The aim of the present study was to evaluate the anti-atherosclerotic activity of ethanolic extract of Chrysanthemum indicum (EECI) flowers against high-fat diet induction in male Wistar rats.

Methods: The method used for induction of atherosclerosis was high-fat diet for 28 days. Rats were divided into five groups (n=6). Group I served as normal. Group II serves as high-fat diet-treated group. Group III serves as standard treated with high-fat diet+atorvastatin (30 mg/kg, p.o). Group IV serves as low dose treated with high-fat diet+EECI (150 mg/kg, p.o.). Group V serves as high dose treated with high-fat diet+EECI ( $300 \mathrm{mg} / \mathrm{kg}$, p.o.). The following parameters, glucose, high-density lipoprotein (HDL), low-density lipoprotein (LDL), total cholesterol (TC), very LDL (VLDL), triglycerides (TG), atherogenic index (AI), serum glutamic oxaloacetic transaminase, serum glutamic pyruvic transaminase, total protein, food consumption, and body weight, were evaluated and histopathological studies were performed.
\end{abstract}

Results: The results showed that EECI at a dose of $150 \mathrm{mg} / \mathrm{kg}$ and $300 \mathrm{mg} / \mathrm{kg}$ exhibited significant decrease in glucose, TG, TC, LDL-cholesterol (LDL-C), HDL, VLDL, AI, and total protein levels when compared to high-fat diet group. This investigation reveals that the extract-treated groups lower the serum TC and LDL-C levels significantly, which reduces the risk of coronary heart disease.

Conclusion: The experimental studies show that the EECI of both doses $150 \mathrm{mg} / \mathrm{kg}$ and $300 \mathrm{mg} / \mathrm{kg}$, respectively, showed significant reduction in lipid profile, glucose, and total protein. From the study, the plant extract showed anti-atherosclerotic activity and thus authenticates its ethnomedicinal use.

Keywords: Atherosclerosis, Atherogenic diet, Chrysanthemum indicum L., Atorvastatin.

(c) 2017 The Authors. Published by Innovare Academic Sciences Pvt Ltd. This is an open access article under the CC BY license (http://creativecommons. org/licenses/by/4. 0/) DOI: http://dx.doi.org/10.22159/ajpcr.2017.v10i9.19463

\section{INTRODUCTION}

Atherosclerosis (also known as arteriosclerotic vascular disease) is a chronic focal disease of the arteries, caused by accumulation of the lipid-containing proteins and cholesterol in the inner wall of the vessel, which leads to the growth of the connecting tissue and the formation of the atherosclerotic plaques. These plaques narrow the artery (which leads to stenosis-narrowing of the arteries) which results in development of a chronic shortage of the blood supply to the body organs [1].

A number of conventional drugs were available for treatment of hyperlipidemia and atherosclerosis, but all of these drugs exhibited serious adverse effects [2]. There was a long history of herbal medicine in the treatment of several kinds of disease [3]. Hence, the use of this herbal medicine for the treatment of disease has been practiced by man for many years and has been practiced even today [4].

Chrysanthemum indicum L. is a perennial herb, belonging to the family Asteraceae. It is mainly used for the treatment of inflammation, hypertension, immunomodulatory, respiratory diseases, and prevention of thrombosis $[5,6]$ and also used as bactericide, antifungal, and antiviral in Indian indigenous system of medicine [7]. C. indicum is reported to possess many chemical constituents such as 1, 8-cineole, camphor, borneol, bornyl acetate flavone and flavone glycosides, and three eudesmane-type sesquiterpenes, kikkanols $\mathrm{A}, \mathrm{B}$, and $\mathrm{C}$ and a trans-eudesmane type sesquiterpene, chrysanthemol, terpenoids, and phenolic compounds [7-11].
In the ethnobotanical claims, the flowers of $C$. indicum are used for the treatment of atherosclerosis. However, there is no scientific report available in support of the anti-atherosclerotic activity of ethanolic extract of $C$. indicum (EECI) flowers. Therefore, to justify the traditional claims, we have assessed the anti-atherosclerotic activity of $C$. indicum by high-fat diet-induced atherosclerosis in male Wistar rats.

\section{METHODS}

Collection of plant material

C. indicum flowers were obtained from the local area of Kadapa District, Andhra Pradesh, India.

\section{Preparation of extract}

The flowers were shade dried, powdered, and sieved (mesh no. 40) to get coarse powder. Then, this powdered plant material was subjected to soxhelation using absolute ethanol as solvent for $72 \mathrm{hrs}$ at a temperature of $40^{\circ} \mathrm{C}$. After filtration, it was evaporated using rotary vacuum evaporator at a temperature not exceeding $40^{\circ} \mathrm{C}$ to get crude extract. The yield was found to be $16.9 \% \mathrm{w} / \mathrm{w}$.

\section{Instruments}

Semi auto analyzer (Maxlyzer, Avecon model no: NB-201), electronic balance (Shimadzu, model no: DS-852 J), micro centrifuge (Remi, model no: KKLO-9013) were used.

\section{Preliminary phytochemical studies}

A preliminary phytochemical analysis was carried out for the qualitative identification of phytoconstituents as per standard procedures $[12,13]$. 
Acute oral toxicity studies

Acute oral toxicity study was carried out in accordance with OECD guidelines no. 423 using male Wistar rats. Four dosing levels (5, 50, 300 , and $2000 \mathrm{mg} / \mathrm{kg}$ ) (p.o.) were considered to carry out acute oral toxicity study. Three animals were selected for single escalating testing dose to observe the signs of toxicity and mortality for 14 days [14].

\section{Experimental animals}

The experimental protocol was carried out using albino male Wistar rats weighing about 120-150 g procured from Raghavendra Enterprises, Bangalore, India and 1-week acclimatization was done as per Committee for the Purpose of Control and Supervision of Experiments on Animals guidelines before the study was carried out. This experimental study was approved by the Institutional Animal Ethical Committee of Sree Vidyanikethan College of Pharmacy, Tirupati, India, with the approval no. SVCP/IAEC/I-006/2013-14.

\section{Induction of atherosclerosis}

The atherosclerosis was induced by atherogenic diet or high-fat diet. The composition of high-fat diet contains $23 \%$ whole wheat, $23 \%$ yellow corn, $11 \%$ barley, $17 \%$ milk powder, $1 \%$ bone meal, $1 \%$ calcium chloride, $1 \%$ sodium chloride, $11 \%$ coconut oil, $11 \%$ butter, and one multivitamin capsule [15]. Administration of atherogenic diet, standard drug, and plant extracts was started on the same day and proceeded for 28 days.

\section{Anti-atherosclerotic activity of EECI}

EECI was freshly suspended in 1\% carboxymethyl cellulose (CMC) and administered to animals by oral feeding needle. The standard drug atorvastatin (ATR) was prepared by suspending in a 1\% CMC using mortar and pestle, made as a suspension and administered immediately.

The animals were randomly selected into five groups, each group comprising 6 animals and treated for 28 days, as given in following treatment schedule. Group I serves as normal, 1\% CMC, Group II was treated with high-fat diet, Group III serves as standard treated with high-fat diet+ATR (30 mg/kg, p.o.), Group IV was treated with high-fat diet+EECI (150 mg/kg, p.o.), and Group V was treated with high-fat diet + EECI (300 mg/kg, p.o.).

\section{Biochemical analysis}

The blood samples were withdrawn on the $28^{\text {th }}$ day from the retroorbital venous plexus of rats without any coagulant for the separation of serum. After collecting the blood into microcentrifuge tubes, it is kept aside for $1 \mathrm{hr}$ at room temperature and then serum was isolated by centrifugation at $2000 \mathrm{rpm}$ for 15 minutes and stored until analyzed for various biochemical parameters.

\section{Histopathology}

For the histological evidence of atherosclerosis, the animals were sacrificed with the high doses of anesthetic ether. The thoracic aorta was dissected out, cleaned of surrounding tissues, longitudinally cut, and opened for fixation with formaldehyde. Aorta is then stained with oil red. The percentage of internal surface covered with oil red positive lesions is calculated with computerized planimeter. In the normal animals, the aorta does not show any staining; however, in the high-fat diet fed animals, the aorta exhibits severe atherogenic lesions stained with oil red.

\section{Statistical analysis}

All the data were expressed as mean \pm standard error of mean using one-way analysis of variance followed by the Dunnett's comparison test using computerized GraphPad prism (version 5.0, trial version, GraphPad software, USA) software at a level of significance of $\mathrm{p}<0.05$.

\section{RESULTS}

\section{Preliminary phytochemical studies}

Preliminary phytochemical studies revealed that EECI showed the presence of flavonoids, glycosides, phenolic compounds, and terpenoids (Table 1).

\section{Acute oral toxicity study}

It was observed that there were no clinical signs of toxicity and mortality for 14 days at a testing dose of $2000 \mathrm{mg} / \mathrm{kg}$. As a result of this, one-tenth of the maximum tolerated dose of DC was selected as therapeutic low dose $(200 \mathrm{mg} / \mathrm{kg}$, DC200) and double of this low dose was considered as the highest dose (400 mg/kg, DC400) for this study (Figs. 1-13) [16].

\section{DISCUSSION}

The present study showed that dietary treatment of rats with highcholesterol diets caused atherosclerotic lesions in an animal model, and these findings were in accordance with earlier studies [17]. Excess amount of cholesterol feeding causes rapid hyperlipidemia and atherosclerosis $[18,19]$.

The statin drugs were accepted as cholesterol-lowering drug in humans [20]. Hence, the standard group was used to compare the effectiveness of the drug in reducing plasma cholesterol levels.

Table 1: Preliminary phytochemical analysis of EECI

\begin{tabular}{lc}
\hline Chemical constituents & EECI \\
\hline Alkaloids & + \\
Flavonoids & + \\
Glycosides & + \\
Terpenoids & + \\
Phenols & + \\
Saponins & + \\
\hline
\end{tabular}

+: Presence, -: Absence, EECI: Ethanolic extract of Chrysanthemum indicum

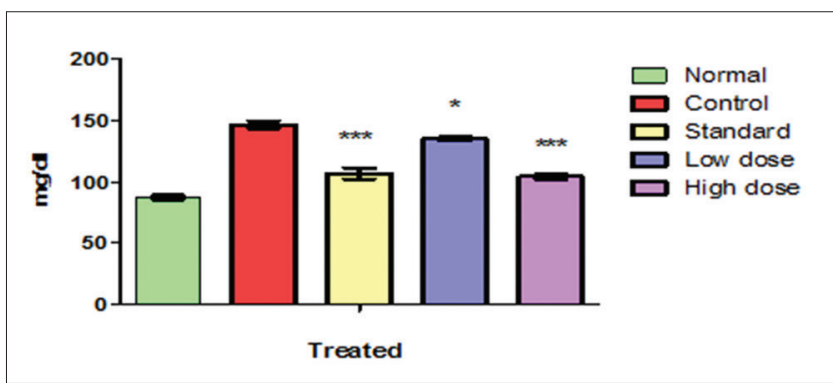

Fig. 1: Effect of ethanolic extract of Chrysanthemum indicum on glucose in high-fat diet-induced atherosclerosis. All values are shown as mean \pm standard of error and $n=6 .{ }^{*} p<0.05,{ }^{* *} p<0.01$, $* * * \mathbf{p}<0.001$ when compared to high-fat diet group

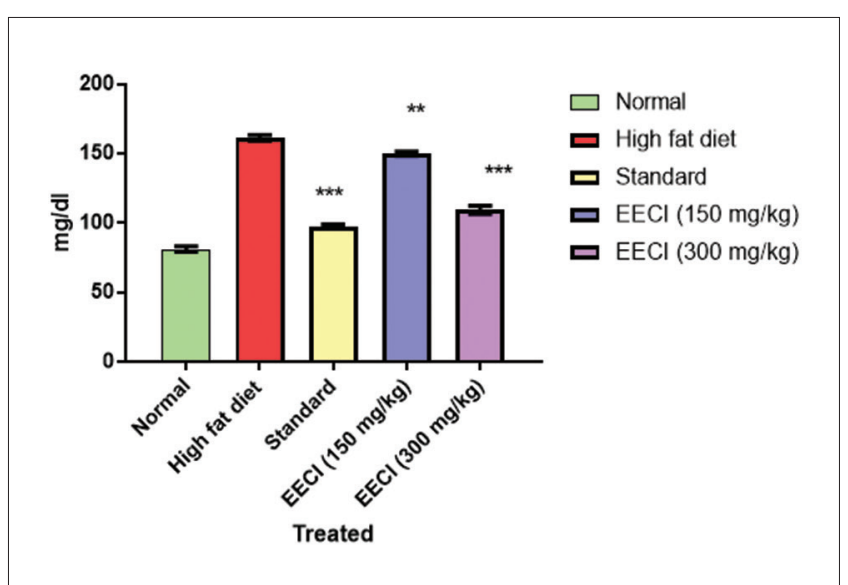

Fig. 2: Effect of ethanolic extract of Chrysanthemum indicum on total cholesterol in high-fat diet-induced atherosclerosis. All values are shown as mean \pm standard of error and $n=6 .{ }^{* *} p<0.01$, $* * * \mathrm{p}<0.001$ when compared to high-fat diet group 


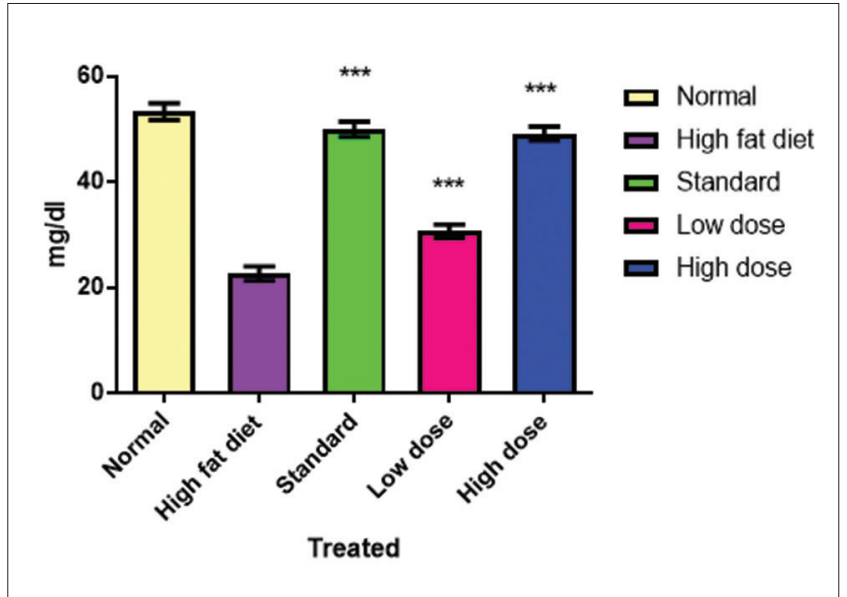

Fig. 3: Effect of ethanolic extract of Chrysanthemum indicum on high-density lipoprotein cholesterol in high-fat diet-induced atherosclerosis. All values are shown as mean \pm standard of error and $\mathbf{n}=6$. ${ }^{* * *} \mathbf{p}<0.001$ when compared to high-fat diet group

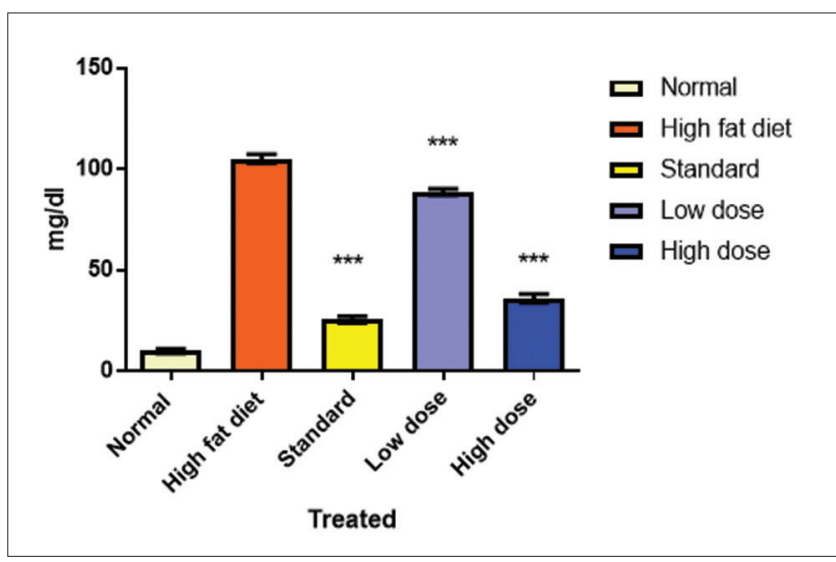

Fig. 4: Effect of ethanolic extract of Chrysanthemum indicum on low-density lipoprotein-cholesterol in high-fat diet-induced atherosclerosis. All values are shown as mean \pm standard of error and $\mathbf{n}=6 .{ }^{* * *} \mathbf{p}<0.001$ when compared to high-fat diet group

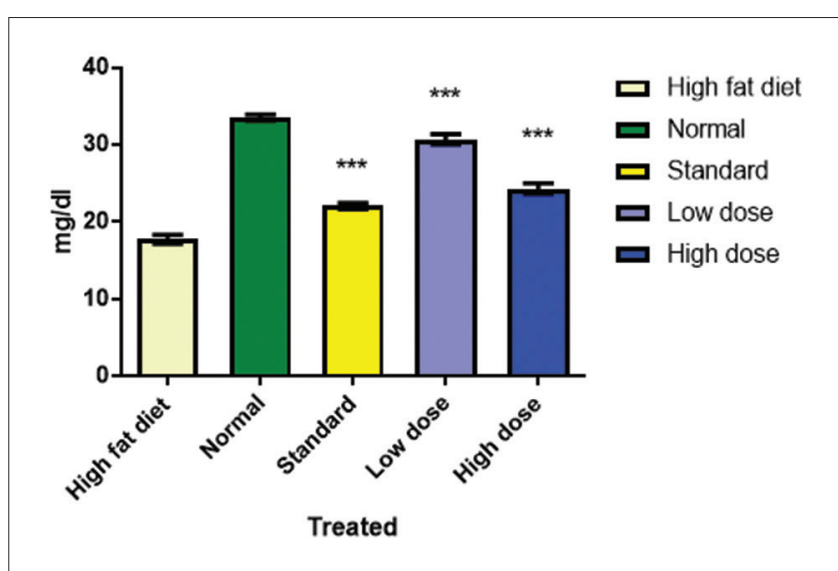

Fig. 5: Effect of ethanolic extract of Chrysanthemum indicum on V low-density lipoprotein-cholesterol in high-fat diet-induced atherosclerosis. All values are shown as mean \pm standard of error and $\mathbf{n}=6 .{ }^{* * *} \mathbf{p}<0.001$ when compared to high-fat diet group

The animal fed with only high-fat diet group for 28 days showed significant increase in the total cholesterol (TC), low-density lipoprotein-cholesterol (LDL)-C when compared with the normal group.

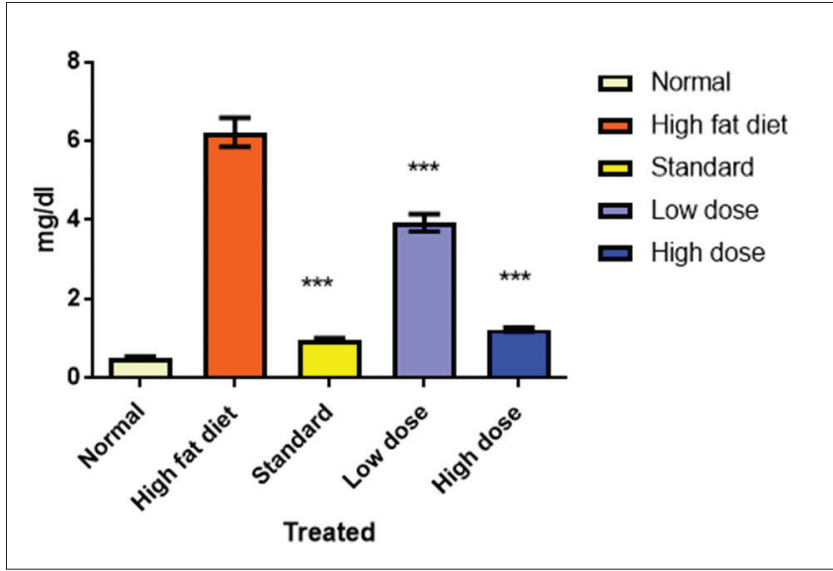

Fig. 6: Effect of ethanolic extract of Chrysanthemum indicum on atherogenic index. All values are shown as mean \pm standard of error and $n=6$. ${ }^{* * *} \mathbf{p}<0.001$ when compared to high-fat diet group

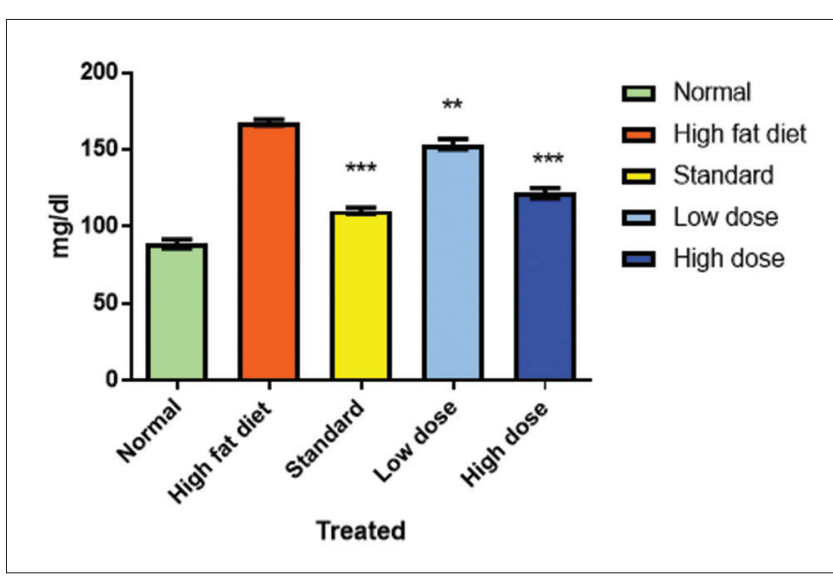

Fig. 7: Effect of ethanolic extract of Chrysanthemum indicum on triglyceride level in high-fat diet-induced atherosclerosis. All values are shown as mean \pm standard of error and $n=6 .{ }^{* *} p<0.01$, ${ }^{* * *} \mathbf{p}<0.001$ when compared to high-fat diet group

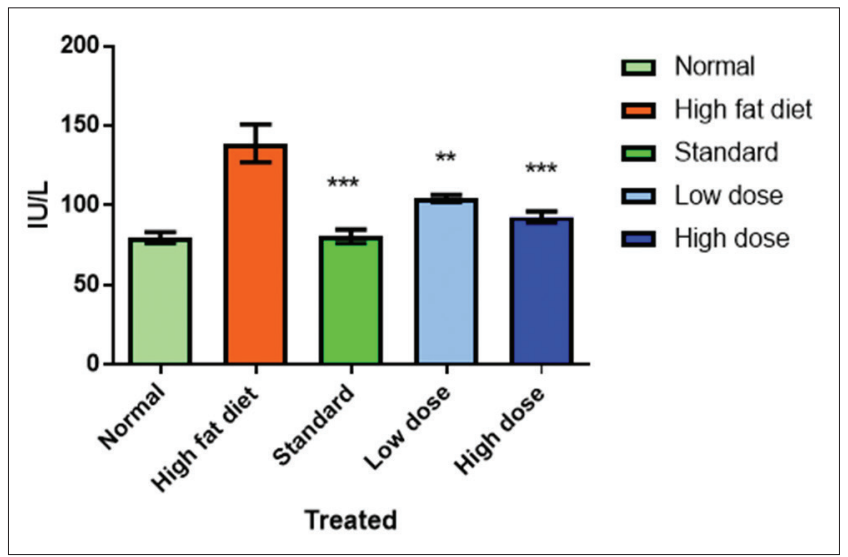

Fig. 8: Effect of ethanolic extract of Chrysanthemum indicum on serum glutamic oxaloacetic transaminase in high-fat diet-induced atherosclerosis. All values are shown as mean \pm standard of error and $\mathbf{n}=6 . * * \mathbf{p}<0.01, * * * \mathrm{p}<0.001$ when compared to high-fat diet group

This increase in TC and LDL-C was due to the increase in cholesterol absorption in the intestines [21]. Based on the present data, the ATRtreated group showed notable decrease in TC, LDL-C, and very LDL 


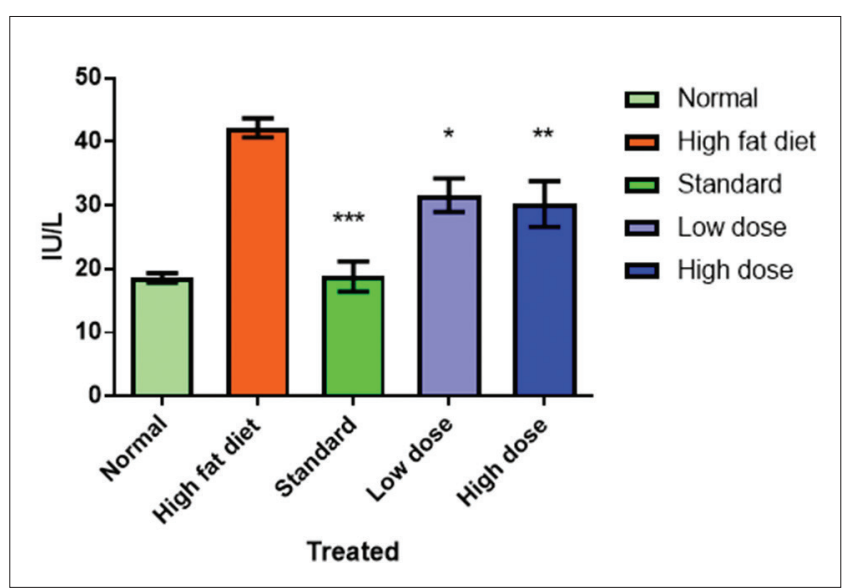

Fig. 9: Effect of ethanolic extract of Chrysanthemum indicum on serum glutamic pyruvic transaminase in high-fat diet-induced atherosclerosis. All values are shown as mean \pm standard of error and $\mathbf{n}=6 .{ }^{*} \mathbf{p}<0.05,{ }^{* *} \mathbf{p}<0.01,{ }^{* * *} \mathbf{p}<0.001$ when compared to highfat diet group

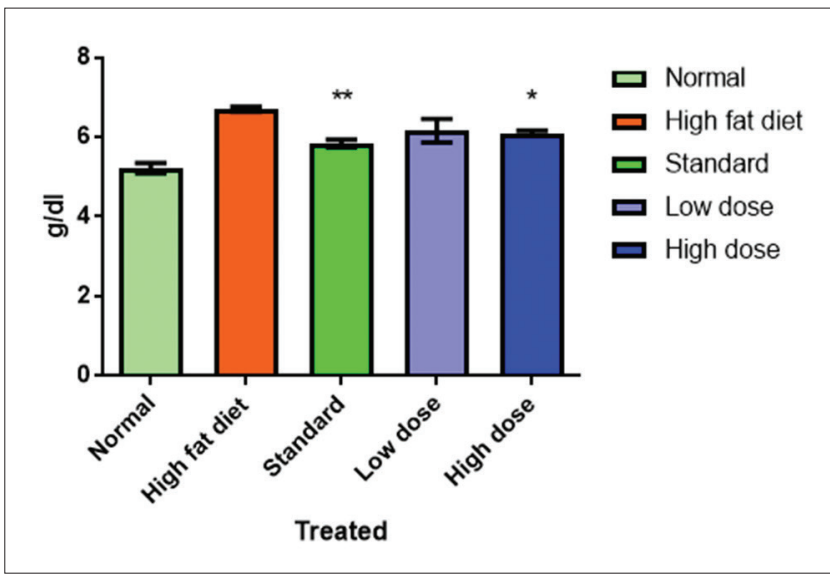

Fig. 10: Effect of ethanolic extract of Chrysanthemum indicum on total protein. All values are shown as mean \pm standard of error and $\mathrm{n}=6 .{ }^{*} \mathbf{p}<0.05,{ }^{* *} \mathbf{p}<0.01$ when compared to high-fat diet group

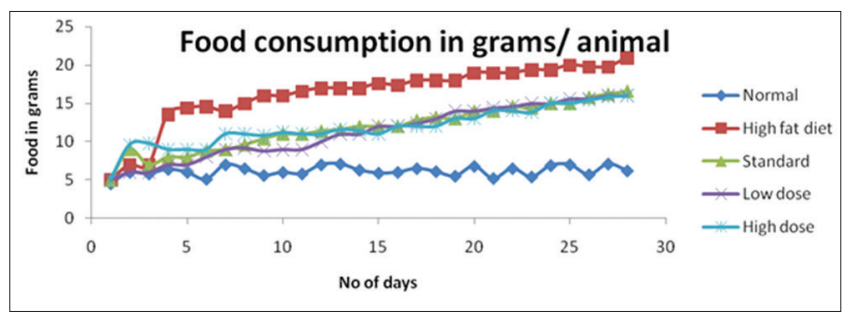

Fig. 11: Effect of ethanolic extract of Chrysanthemum indicum on food consumption

levels. EECI at a dose of $150 \mathrm{mg} / \mathrm{kg}$ and $300 \mathrm{mg} / \mathrm{kg}$ showed significant dose-dependent decrease in TC, LDL-C levels when compared to highfat diet group. This investigation reveals that the plant extract feeding lowers the serum TC and LDL-C levels significantly, which reduces the risk of coronary heart disease.

In the present study, animals treated with ATR and high-fat diet showed significant increase in high-density lipoprotein (HDL) level. EECI of $300 \mathrm{mg} / \mathrm{kg}$ showed progressive increase in HDL-C level when compared to high-fat diet group. C. indicum flower extract-treated groups had restored the HDL-C level to the normal. The rats which are treated with high-fat diet showed increased plasma triglycerides (TG)

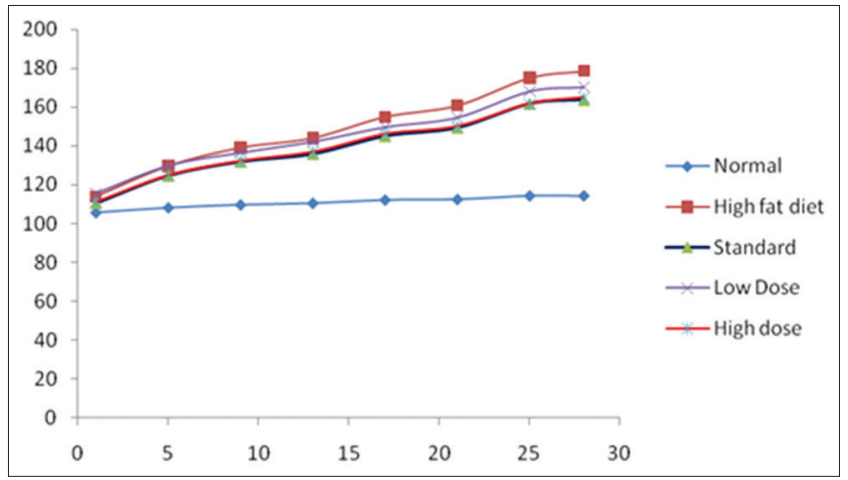

Fig. 12: Effect of ethanolic extract of Chrysanthemum indicum on body weight
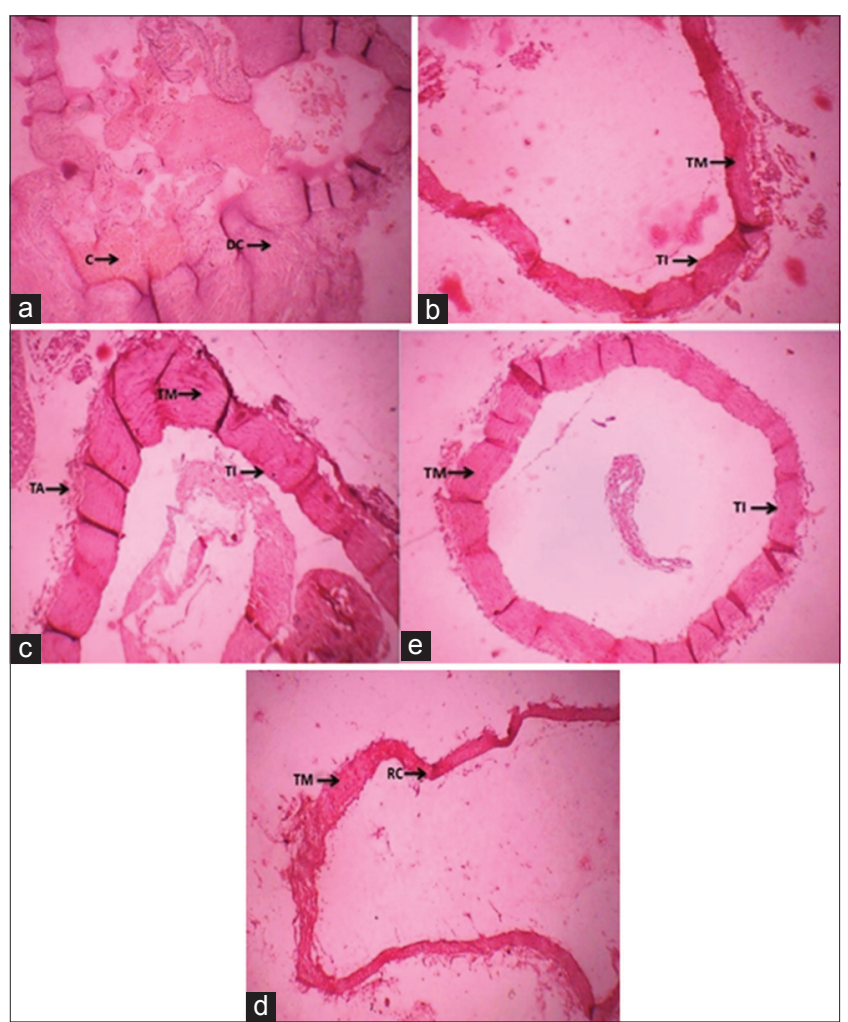

Fig. 13: Histopathology of aorta (a) normal (1\% carboxymethyl cellulose), (b) standard (high-fat diet [HFD]+atorvastatin $30 \mathrm{mg} / \mathrm{kg}$ ), (c) low dose (HFD+ethanolic extract of Chrysanthemum indicum [EECI] $150 \mathrm{mg} / \mathrm{kg}$ ), (d) high dose (HFD+EECI $300 \mathrm{mg} / \mathrm{kg}$ ). TM=Tunica medium, TI=Tunica intima, $\mathrm{TA}=$ Tunica adventitia, $\mathrm{DC}=$ Degenerative changes, $\mathrm{C}=$ Congestion, RC= Regenerative changes, (e) HFD (High Fat Diet)

levels. Animals treated with ATR and EECI showed significant decrease in triglyceride level. Ethanol extract of flowers of $C$. indicum at a dose of $150 \mathrm{mg} / \mathrm{kg}$ and $300 \mathrm{mg} / \mathrm{kg}$ showed dose-dependent reduction in TG level when compared to high-fat diet group.

The food intake and body weight in all groups were increased throughout the experimental period. At the end of study, the highest body weight was found in the high-fat diet group. This increase in the body weight was due to greater lipid deposition in the body tissue of the animal in accordance with a previous study by Lee et al. [21] and Weintraub [22].

Higher food intake in the high-fat diet group could have been due to high satiety. However, the lowest food intake in standard group might be due to distaste for ATR [21]. ATR-treated group showed reduced food 
intake and body weight. EECI at a dose of $150 \mathrm{mg} / \mathrm{kg}$ and $300 \mathrm{mg} / \mathrm{kg}$ showed dose-dependent decrease in the food intake and body weight when compared to the high-fat diet group.

In histopathological studies, the aorta in the high-fat diet group animals showed a statistically significant increase in the intimal thickening and the spaces within the tunica intima and tunica media and also formation of the lipoidal layer in the intima of artery. This increase in the spaces might be attributed to the free radicals that could damage the membranes and DNA of the endothelial cells in the tunica intima and the smooth muscle cells in the tunica media. Therefore, it was clear that the high-fat diet group showed notable increase in lipid composition levels in the aorta [23]. ATR-treated group had showed significant decrease in the intimal thickening and the spaces within the tunica intima and tunica media. The absence of such lipoidal layer and decrease in the intimal thickening and the spaces within the tunica intima and tunica mediain of EECI high dose $300 \mathrm{mg} / \mathrm{kg}$ shows effectiveness of drug against hyperlipidemia and atherosclerosis.

\section{CONCLUSION}

The cholesterol lowering effect of the plant extract might be decrease in intestinal absorption of cholesterol by increasing in the fecal excretion of neutral lipids [24]. The anti-atherosclerosis activity of EECI might be due to the presence of phytoconstituents. Thus, it validated the traditional use as an ethnomedicine against atherosclerosis. However, further studies are needed to identify and characterize the phytoconstituents from EECI and also to explore the exact mechanism to act as anti-atherosclerotic, before being establish it in clinical setting.

\section{ACKNOWLEDGMENT}

The authors wish to thank the principal Dr. C. K. Ashok Kumar, Sree Vidyanikethan College of Pharmacy and to the Management of Sree Vidyanikethan Group of Institutions for providing the necessary facilities to carry out the research work.

\section{REFERENCES}

1. Maton A, Hopkins J, McLaughlin CW. Human Biology and Health. New Jersy, USA: Prentice Hall, Englewood Cliffs; 1993.

2. Knopp RH. Drug treatment of lipid disorders. N Engl J Med 1999;341(7):498-511.

3. Holm G, Herbst V, Teil B. Brogenkunde. Plant Med 2001;67:263-9.

4. Kokwaro JO. Medicinal Plants of East Africa. $2^{\text {nd }}$ ed. Nairobi: Kenya Literature Bureau; 1993.

5. Cheng W, Li J, You T, Hu C. Anti-inflammatory and immunomodulatory activities of the extracts from the inflorescence of Chrysanthemum indicum Linné. J Ethnopharmacol 2005;101(1-3):334-7.

6. Levy JV, Xie ZF. Effect of three Chinese herbal medicines (Ligustrazine, Chrysanthemum indicum, Salvia emiltiorrhizae) on PAF and ADP- induced platelet aggregation in vitro. Prostaglandins 1988;35(5):842.

7. Shunying Z, Yang Y, Huaidong Y, Yue Y, Guolin Z. Chemical composition and antimicrobial activity of the essential oils of Chrysanthemum indicum. J Ethnopharmacol 2005;96(1-2):151-8.

8. Uchio $\mathrm{Y}$, Tomosue $\mathrm{K}$, Nakayama M, Yamammura A, Waki T. Constituents of the essential oil from three tetraploid species of chrysanthemum. Phytochemistry 1981;20(12):2691-3.

9. Yoshikawa M, Morikawa T, Murakami T, Toguchida I, Harima S, Matsuda H. Medicinal flowers. I. Aldose reductase inhibitors and three new eudesmane-type sesquiterpenes, kikkanols A, B, and C, from the flowers of Chrysanthemum indicum L. Chem Pharm Bull (Tokyo) 1999;47(3):340-5

10. Mou LY, Zhu LY, Lin ZY, Liang XT Stereoselective total synthesis of chrysanthemol. J Asian Nat Prod Res 2001;3(2):103-16.

11. Cheon MS, Yoon T, Lee DY, Choi G, Moon BC, Lee AY, et al. Chrysanthemum indicum Linné extract inhibits the inflammatory response by suppressing NF-kappaB and MAPKs activation in lipopolysaccharide-induced RAW 264.7 macrophages. J Ethnopharmacol 2009;122(3):473-7.

12. Trease GE, Evans WC. Textbook of Pharmacognosy. $12^{\text {th }}$ ed. London: Bailliere Tindall; 1989

13. Kokate CK, Purohit AP, Gokhale SB. Practical Pharmacognosy. $2^{\text {nd }}$ ed. Mumbai, Pune: Nirali Prakashan; 1994

14. Sun YP, Lu NC, Parmley WW, Hollenbeck CB. Effects of cholesterol diets on vascular function and atherogenesis in rabbits. Proc Soc Exp Biol Med 2000;224(3):166-71.

15. Ramgopal M, Attitalla I, Avinash P, Meriga B. Evaluation of antilipidemic and anti-obesity efficacy of Bauhinia purpurea bark extract on rats fed with high fat diet. Acad J Plant Sci 2010;3(3):104-7.

16. Amran AA, Zaiton Z, Faizah O, Morat P. Effects of Garcinia atroviridis on serum profiles and atherosclerotic lesions in the aorta of guinea pigs fed a high cholesterol diet. Singapore Med J 2009;50(3):295-9.

17. Yamakoshi $\mathrm{J}$, Piskula MK, Izumi $\mathrm{T}$, Tobe $\mathrm{K}$, Saito $\mathrm{M}$, Kataoka S, et al. Isoflavone aglycone-rich extract without soy protein attenuates atherosclerosis development in cholesterol-fed rabbits. J Nutr 2000;130(8):1887-93.

18. Rauch U, Osende JJ, Chasebro JH, Fuster V, Vorchheimer DA, Harris K, et al. Statin and cardiovascular disease: The multiple effects of lipid-lowering therapy by statin. Atherosclerosis 2002;153:181-9.

19. Rosenson RS. Statins in atherosclerosis. Atherosclerosis 2004;173:1-12.

20. Chen C, Liu L, Hsu J, Huang H, Yang M, Wang C. Mulberry extract inhibits the development of atherosclerosis in cholesterol-fed-rabbits. Food Chem 2005;91:601-7.

21. Lee HS, Ahn HC, Ku SK. Hypolipemic effect of water extracts of Picrorrhiza rhizoma in PX-407 induced hyperlipemic ICR mouse model with hepatoprotective effects: a prevention study. J Ethnopharmacol 2006;105(3):380-6.

22. Weintraub H. Atorvastatin 80mg: If You Can't Go Lower, Go Elsewhere. In Medscape News; 2011.

23. Hur SJ, Du M, Nam K, Williamson M, Ahn DU. Effect of dietary fats on blood cholesterol and lipid and the development of atherosclerosis in rabbits. Nutr Res 2005;25:925-35.

24. Purohit A, Vyas KB. Antiatherosclerotic effect of Capparisdeciduas fruit extract in cholesterol-fed rabbits. Pharm Biol 2006;44:172-7. 